Mathematical Modelling and Analysis

Volume 8 Number 3, 2003, pages 175-179

(C) 2003 Technika, ISSN 1392-6292

\title{
ON THE DEVIATION OF MILIN'S FUNCTIONAL
}

\section{ALEKSANDROV, T. KASATKINA and A. ALEKSANDROV}

Tomsk State University

Lenin 36, Tomsk 634050, Russia

E-mail: ustinov@ctc.tsu.ru

Received December 03 2001; revised February 262003

\section{ABSTRACT}

The goal of the present paper is to formulate the problem of investigation of the deviation of Milin's functional for the holomorphic in the unit disk function or on the whole class $S$. The first results of such investigations are presented.

Key words: holomorphic functions, unit disk functions, Milin's functional

\section{INTRODUCTION}

In the middle of the twentieth century N. Lebedev and I. Milin [3] have proved the inequality

$$
\left|C_{n}(f)\right| \leq n \exp \left\{-M_{n}(f)\right\}(n=2,3, \ldots)
$$

where $M_{n}(f)$ is Milin's functional.

In 1971 Milin formulated the hypothesis $M_{n}(f) \geq 0$ for every function $f \in S$ and for every $n \in \mathbb{N}\{1\}$ in [4]. The validity of the hypotheses has been proved by L. de Branzes in 1984 [2].

\section{THE PROBLEM AND ITS INVESTIGATION}

Let $D_{n}$ be the range of the Milin's functional

$$
M_{n}(f)=\frac{1}{n} \sum_{k=1}^{n-1} \frac{n-k}{k}\left(1-k^{2}\left|\gamma_{k}(f)\right|^{2}\right) \quad(n=2,3, \ldots)
$$


on the class $S$ of functions

$$
f(z)=z+c_{2}(f) z^{2}+\ldots+c_{n}(f) z^{n}+\cdots
$$

which are holomorphic and univalent in the unit disk $E=\{z:|z|<1\}$. $D_{n}$ is the segment with the endpoints 0 and $m_{n}=\sum_{k=2}^{n} \frac{1}{k}$ [2]. In (2.1) we use the notation $\gamma_{k}(f)$ for the logarithmic coefficients of the function $f$, i.e. the coefficients of the expansion

$$
\frac{1}{2} \ln \frac{f(z)}{z}=\gamma_{1}(f) z+\ldots+\gamma_{k}(f) z^{k}+\ldots
$$

The left-side boundary point in $D_{n}$ is contributed by every Kebe function

$$
K_{\varphi}(z)=\frac{z}{\left(1-e^{i \varphi} z\right)^{2}}, \quad 0 \leq \varphi \leq 2 \pi
$$

while the right-side boundary point is contributed by the identity mapping

$$
f_{0}(z)=z
$$

Obviously, $D_{n} \subset D_{n+1}$ and the sequence $\left\{m_{n}\right\}_{n=2}^{\infty}$ increases monotonously from $1 / 2$ to $\infty$.

Let

$$
\Delta_{n}(f)=M_{n+1}(f)-M_{n}(f)=\frac{1}{n(n+1)} \sum_{k=1}^{n}\left(1-k^{2}\left|\gamma_{k}(f)\right|^{2}\right)
$$

be the deviation of Milin's functional. Since

$$
\Delta_{n}\left(K_{\varphi}\right)=0, \Delta_{n}\left(f_{0}\right)=1 /(n+1)
$$

then

$$
a_{n}(\widetilde{S}) \equiv \inf _{f \in \widetilde{S}} \Delta_{n}(f) \leq 0<1 /(n+1) \leq \sup _{f \in \widetilde{S}} \Delta_{n} \equiv b_{n}(\widetilde{S})
$$

The problem consists of constructing the upper and lower estimates of $\Delta_{n}(f)$, determining $a_{n}(\widetilde{S}), b_{n}(\widetilde{S})(n=2,3, \ldots)$ for $\widetilde{S}=S$ or some other choice of $\widetilde{S}$, and in checking the validity of the following proposition: $a_{n}(S)=0$ for $n=2,3, \ldots$ We assume that the function $f \in S^{\prime}$, if $f \in S$, and it maps the disk $E$ into the plane containing the slit along the generalized Jordan arc not containing zero and joining the point $\infty$ with some point $q(f) \in C \backslash\{0\}$. This 
$\operatorname{arc} L(f, 0)$ which is located outside the disk $|w|<\frac{1}{4}$ can be parametrized in a way [1], that

$$
\begin{aligned}
& L(f, 0)=\{w: w=\varphi(t)\}, \quad 0 \leq t \leq \infty \\
& \varphi(0)=q(f), \quad \varphi(\infty)=\infty
\end{aligned}
$$

and, in addition, the function $\Psi(z, \tau)$, mapping $E$ into the plane with the shortened slit

$$
L(f, \tau)=\{w: w=\varphi(t)\}, 0<\tau \leq t \leq \infty,
$$

has the norm $\Psi(z, \tau)=e^{\tau} z+\ldots$ and satisfies the Levner equation

$$
\frac{\partial \Psi}{\partial \tau}=z \frac{\partial \Psi}{\partial \tau} \frac{\mu(\tau)+z}{\mu(\tau)-z}, 0<\tau<\infty,
$$

where $\Psi(\mu(\tau), \tau)=\varphi(\tau)$ and $\mu(\tau)$ is the original of the moving end of the slit $L(f, \tau)$.

The set of all functions $f \in S^{\prime}$ is dense in $S$. The set $S^{\prime}$ can be obtained as a collection of all functions $f(z)=\Psi(z, 0)$, where $\Psi(z, \tau)$ is the solution of equation (2.2), with $\mu(\tau)$ being a continuous function of unit modulus.

Let $f \in S^{\prime}$. Putting the expansion

$$
\frac{1}{2} \ln \frac{\Psi(z, \tau)}{e^{\tau} z}=\Gamma_{1}(\tau) z+\ldots+\Gamma_{k}(\tau) z^{k}+\ldots
$$

into (2.2) we obtain the following equation:

$$
1+2 \sum_{k=1}^{\infty} \Gamma_{k}^{\prime}(\tau) z^{k}=\left[1+2 \sum_{k=1}^{\infty} k \Gamma_{k}(\tau) z^{k}\right]\left[1+2 \sum_{k=1}^{\infty} \bar{\mu}(\tau)^{k} z^{k}\right] .
$$

Equating the coefficients at the same powers of $z$ we obtain the equations determining the logarithmic coefficients of the equation

$$
\Gamma_{k}^{\prime}(\tau)=k \Gamma_{k}(\tau)+2 \bar{\mu}(\tau)^{k} \beta_{k-1}(\tau)(k=1,2, \ldots),
$$

where

$$
\beta_{0}(\tau)=\frac{1}{2}, \beta_{k}(\tau)=\frac{1}{2}+\sum_{m=1}^{k} m \Gamma_{m}(\tau) \mu(\tau)^{m},(k=1,2, \ldots) .
$$

The uniform convergence of $\Psi(z, \tau)$ to $f(z)$ inside $E$ implies

$$
\Gamma_{k}(0)=\gamma_{k}(f)(k=1,2, \ldots) .
$$


The formula

$$
\Gamma_{k}(\tau)=e^{k \tau}\left[\gamma_{k}(f)+2 \int_{0}^{\tau} e^{-k s} \bar{\mu}(s)^{k} \beta_{k-1}(s) d s\right]
$$

allows us to determine $\Gamma_{1}(\tau), \Gamma_{2}(\tau), \ldots$ sequentially. In particular,

$$
\begin{gathered}
\Gamma_{1}(\tau)=e^{\tau}\left[\gamma_{1}(f)+\int_{0}^{\tau} e^{-s} \bar{\mu}(s) d s\right] \\
\Gamma_{2}(\tau)=\Gamma_{1}^{2}(\tau)+e^{2 \tau}\left[\gamma_{2}(f)-\gamma_{1}^{2}(f)+\int_{0}^{\tau} e^{-2 \tau} \bar{\mu}(s)^{2} d s\right],
\end{gathered}
$$

which implies the integral representations of $\gamma_{1}(f), \gamma_{2}(f)$

$$
\gamma_{1}(f)=-\int_{0}^{\infty} e^{-s} \bar{\mu}(s) d s=\frac{1}{2} c_{2}(f), \gamma_{2}(f)=\gamma_{1}^{2}(f)+\int_{0}^{\infty} e^{-2 s} \bar{\mu}(s)^{2} d s .
$$

This implies

$$
\left|c_{2}(f)\right|=2\left|\gamma_{1}(f)\right| \leq 2
$$

and by applying the variational techniques [4] we obtain

$$
\left|\gamma_{2}(f)\right| \leq 1 / 2+1 / e^{2}
$$

for any function $f \in S$. Now let us investigate the function

$$
\Lambda_{n}(\tau)=\Delta_{n}\left(e^{-\tau} \Psi\right)=\frac{1}{n(n+1)} \sum_{k=1}^{n}\left(1-k^{2}\left|\Gamma_{k}(\tau)\right|^{2}\right) .
$$

We notice that $\Lambda_{n}(0)=\Delta_{n}(f)$. We shall find out the conditions for which $\Lambda_{n}(0) \geq \Lambda(\infty)$. By taking the derivative of $\Lambda_{n}(\tau)$, we obtain

$$
\begin{aligned}
n(n+1) \Lambda_{n}^{\prime}(\tau) & =-2 \sum_{k=1}^{n} k^{2} \operatorname{Re}\left(\bar{\Gamma}_{k} \Gamma_{k}^{\prime}\right)=-2 \sum_{k=1}^{n} k\left(\left|\beta_{k}\right|^{2}-\left|\beta_{k-1}\right|^{2}\right) \\
& =-2\left[n\left|\beta_{n}\right|^{2}-\sum_{k=1}^{n-1}\left|\beta_{k}\right|^{2}-\frac{1}{4}\right] .
\end{aligned}
$$


The inequality

$$
\left|\beta_{1}\right|^{2}-\frac{1}{4}=\left|\frac{1}{2}+\Gamma_{1}(\tau) \mu(\tau)\right|^{2}-\frac{1}{4} \geq 0, \quad 0<\tau<\infty
$$

is valid for $\Gamma_{1}(\tau) \mu(\tau)$ located outside the disk with the center at $-1 / 2$ of the radius $1 / 2$. Taking inequality $\left|\Gamma_{1}(\tau) \mu(\tau)\right| \leq 1$ into account we get that $\Lambda_{n}^{\prime}(\tau) \leq 0$, if $\Gamma_{1}(\mu) \mu(\tau)$ is located in the closure of the unit disk where the disk of the radius $1 / 2$ with the center at the point $-1 / 2$ is cut off. For this set the inequality $\Lambda_{n}^{\prime}(\tau) \leq 0$ holds. Consequently,

$$
\Delta_{n}(f) \geq \Lambda(\infty), \quad \Delta_{n}(f) \geq 0
$$

thus $\Lambda(\infty) \geq 0$. An example of a function satisfying these conditions is a Kebe function.

\section{REFERENCES}

[1] I.A. Aleksandrov. Parametricheskye prodolzhenija v teorii odnolistnych funkcii. M.: Nauka, 1976. (in Russian)

[2] Louis de Branges. A proof of the Bieberbach conjecture. Acta Math., 154(1-2), 137 $1527,1985$.

[3] N.A. Lebedev and I.M. Milin. Ob odnom neravenstve. Vestnic Leningradskogo un-ta, 19, 157, 1965.

[4] I.M. Milin. Odnolistnye funkcii i ortonorrovanye sistemy. M. Nauka, 1971. (in Russian)

\section{Milino funkcijos nuokrypis}

I. Aleksandrov, T. Kasatkina, A. Aleksandrov

Straipsnyje nagrinėjamas funkcionalas, kurị pirmasis apibrěžè ir vèliau tyrè L.de Branzes. Konstruojami šio funkcionalo koeficientų įverčiai, kurie gali būti naudingi kompleksinio kintamojo funkcijoms tirti. Pateikti tokios analizès pirmieji pavyzdžiai. 